\title{
POR UMA GEOGRAFIA DAS EMOÇÕES
}

\author{
Marcia Alves Soares Da Silva ${ }^{1}$
}

Resumo: Pensar as emoções dentro da perspectiva geográfica é um desafio, visto que rompe com uma tradição positivista, em que as questões mais subjetivas não são relevantes. A geografia das emoções recentemente ganha espaço nas abordagens geográficas, na qual se percebe a importância do debate em outras áreas do conhecimento, como a Antropologia, Sociologia e Psicologia, mas busca avançar na temática, discutindo as emoções a partir da relação com os lugares, isto é, através de uma perspectiva espacial. A metodologia deste trabalho se dá a partir da discussão teórico-conceitual baseada em referências sobre o tema. De maneira concisa, serão apresentadas as discussões sobre as emoções em algumas áreas do conhecimento pertinentes ao debate geográfico, as recentes contribuições sobre a geografia das emoções e as possibilidades de pensar as questões emocionais no espaço urbano.

Palavras-chave: Emoções. Lugares. Espaço urbano. Corpo. Geografias emocionais.

\section{FOR A GEOGRAPHY OF EMOTIONS}

Abstract: Thinking emotions within the geographical perspective is a challenge, since it breaks with a positivist tradition in which the more subjective issues are not relevant. The geography of emotions has recently earned ground in the geographical approaches, when the importance of the debate in other areas of knowledge, such as Anthropology, Sociology and Psychology is realized, but it seeks to advance in the subject, discussing emotions from the relationship with places, this is, through a spatial perspective. The methodology of this work is given from the theoretical and conceptual discussions based on references of the subject. Concisely, discussions will be presented on the emotions in some areas of knowledge that are relevant to the geographical debate, recent contributions on the geography of emotions and the possibilities of thinking about emotional issues in urban space.

Keywords: Emotions. Places. Urban space. Body. Emotional geographies.

\footnotetext{
${ }^{1}$ Doutoranda no Programa de Pós-Graduação em Geografia da Universidade Federal do Paraná (UFPR). Contato:marcia.alves.geo@gmail.com
} 


\section{Introdução}

Nossa relação com o espaço não é meramente visual ou corpórea, mas também é envolvida por emoções, possibilitadas a partir das nossas experiências e vivências. Muitas das experiências cotidianas envolvidas pelas emoções são "despertadas" em distintos lugares, isto é, há lugares significativos em que as emoções ficam mais evidentes, podendo ser positivas ou negativas.

Determinados contextos, processos históricos e práticas culturais vão modificar nossa relação com o espaço. Num olhar geográfico sobre a questão, nossas relações espaciais e sociais estão envolvidas por questões emocionais. Assim, podemos compreender as emoções enquanto fatos espaciais. Nesse sentido, a geografia das emoções defende a ideia de que as emoções são também fenômenos espaciais, avançando nas discussões propostas por outras áreas de conhecimento que apresentam o tema a partir de questões sociais, culturais, biológicas e psicológicas.

Qual a relação entre emoção e lugares? Quais as dimensões emocionais das representações espaciais? Como compreender a relação corpo e emoção com o urbano, os lugares, a construção social da cidade? São algumas das indagações colocadas pela geografia das emoções, na qual as pessoas são a discussão central, possibilitando uma geografia sensível, que privilegie as subjetividades presentes nas vivências espaciais.

Essa perspectiva vê as emoções por meio de eventos espaciais, sendo o conceito de "lugar" o mais apropriado para compreender a discussão, visto que tal conceito prioriza as experiências, vivências e sentimentos das pessoas. Colocar as pessoas como centrais nas discussões da Geografia, especialmente a partir de suas vivências e experiências, traduzidas a partir de suas narrativas, rompe com uma tradição geográfica que é/está desinteressada em questões mais subjetivas presentes no nosso cotidiano e na relação com o espaço. Propomos pensar a cidade a partir das pessoas e suas espacialidades, buscando discutir as relações emocionais com os lugares.

A geografia das emoções claramente não se restringe ao espaço urbano e à cidade, mas também pode ser compreendida a partir de outros lugares. Contudo, nossa proposta neste debate é pensar o espaço urbano desde uma ótica mais subjetiva, em especial relacionado às emoções, que podem não ser visíveis num primeiro momento, mas fazem parte de nossas vivências espaciais. Assim, compreendemos que as emoções são inerentes ao ser humano $e$ são despertadas por diferentes estímulos, dentre eles a nossa experiência nos lugares.

No primeiro momento, a proposta apresentará diferentes abordagens sobre o conceito de emoções, a partir de outras áreas do conhecimento, sendo muitas delas de importante influência na Geografia. O segundo ponto do trabalho apresentará os debates recentes sobre a geografia das emoções, especialmente a partir das contribuições da geografia europeia e norte-americana, buscando uma compreensão mais abrangente sobre a temática. Por fim, a discussão irá apresentar a proposta de 
pensar o espaço urbano a partir da geografia das emoções, privilegiando as experiências emocionais das pessoas no contexto urbano.

\section{O que são as emoções?}

A discussão sobre as emoções tem sido objeto de estudo de diferentes correntes de pensamento, o que demonstra a complexidade do tema. As emoções são analisadas a partir de um viés biológico, psicológico, de relações sociais, culturais e comportamentais, até mesmo com teorias evolutivas sobre a questão.

Oatley e Jenkins (2002) apresentam algumas abordagens sobre as emoções, como a biológica (discutida por Charles Darwin), a corporal (proposta por William James) e a psicoterapêutica (a partir das contribuições de Sigmund Freud). Além disso, apresentam o debate das emoções enquanto construção cultural, devido ao fato de derivarem dos significados humanos que são necessariamente culturais. Para os autores, as emoções são afetadas pelas ideias culturais, isto é, são produtos culturais, como as linguagens ou as obras de arte.

As emoções humanas são a linguagem da vida social humana - fornecem os padrões de contorno que relacionam as pessoas umas com as outras - e são intencionais, em que a intencionalidade neste sentido filosófico significa "com o propósito de". Os estados mentais conscientes nos humanos têm motivos: os humanos possuem crenças acerca de coisas, desejos de coisas etc. (OATLEY; JENKINS, 2002).

Os autores afirmam que as emoções, por vezes, são abordadas como "extras" na vida das pessoas. Eles, no entanto, defendem a ideia de que as emoções são o próprio centro da vida mental humana, ligando o que é importante para nós com o mundo das pessoas, das coisas e dos acontecimentos, proporcionando infraestrutura para a vida social. Assim, as emoções são estruturas de orientação das nossas vidas, especialmente das nossas relações com os outros.

Nesse sentido, Ragassi (1998) afirma que a emoção ocorre quando há um sujeito emocionado e um objeto emocionador. Assim, a emoção se nutre de um objeto e tem consciência desse objeto. Na visão da geografia das emoções podemos pensar o objeto enquanto espaço/lugar, em que a pessoa, ao estar diante de determinados lugares, estes lhe despertam diferentes emoções.

Nossa relação com o mundo se dá a partir do corpo, em que corpo e consciência são coextensivos. Corpo/consciência age sobre as coisas, organiza o mundo e constitui as pessoas como parte deste mundo. Nesse sentido, não há consciência sem o mundo e não há mundo sem a consciência. O objeto depende da consciência para ser demarcado enquanto um singular-universal (RAGASSI, 1998; FRANCISCO, 1998). 
A emoção, como já foi dito, é um fenômeno completo que precisa ser compreendido no seu conjunto e, quando nos emocionamos, é sempre em relação a alguma coisa que o fazemos. O corpo, enquanto experiência imediata da consciência, isto é, o corpo que somos, embarca de todo nessa nova atitude frente ao mundo. (FRANCISCO, 1998, p. 157).

Teixeira (1998) apresenta uma discussão intrigante ao afirmar que a emoção faz parte da realidade humana, pois possui um "papel funcional", mas não é produto da subjetividade do sujeito. O autor afirma que "Quando me emociono frente a alguma coisa, minha emoção dirige-se para o mundo, é consciência do mundo e nele se sustenta. O que me emociona está fora de mim, está no mundo, é uma coisa entre as coisas [...]" (TEIXEIRA, 1998, p. 134).

Assim, as pessoas são resultado de um processo de relações corpo/consciência com as coisas, consigo mesmas e com o tempo (passado e futuro). Além disso, as emoções "ocorrem no conjunto de uma personalidade, o que envolve um projeto e um desejo de ser. Possui uma significação funcional no conjunto da vida psíquica como um todo e é essencialmente um fenômeno de crença" (FRANCISCO, 1998, p. 158).

Embora haja pesquisas que busquem analisar as emoções a partir de um viés biológico e psicológico, relacionando-as com a nossa própria evolução biológica, a geografia das emoções busca articular sua perspectiva a partir de questões mais voltadas para o social e o cultural. A Antropologia e a Sociologia das emoções têm proposto, desde a década de 1970, o estudo sobre as emoções. Esses estudos entram a partir de novas formulações teóricas e metodológicas que enfatizavam um processo analítico da subjetividade como fonte e forma de expressão e construção social. Tais formulações surgem como crítica à lógica linear das análises sociais de cunho mais estrutural que relegavam para segundo plano a ação social individual, atores sociais e a vida emocional (KOURY, 2009).

Conforme o autor, a proposta dessas análises é compreender os fenômenos emocionais como fenômenos sociológicos. Há visões mais "radicais" que consideram as emoções como "processos eminentemente sociais, não cabendo sequer a questão teórica de que as emoções não sejam socialmente construídas" (KOURY, 2009, p. 8). Koury (2009) afirma que as emoções são pensadas de uma maneira própria, mas podem ser construídas e constituídas socialmente e culturalmente, e são possuidoras de significado apenas no contexto cultural e social em que foram produzidas e que foi por elas experimentado. Por contexto podemos compreender, a partir de um olhar geográfico, não só as relações sociais e culturais, debatidas pela Sociologia, como apresenta o autor, mas também o contexto espacial, isto é, os lugares.

A sociologia das emoções parte do princípio de que as experiências emocionais singulares, sentidas e vividas por um ator social específico, são produtos relacionais 
entre os indivíduos e a cultura e a sociedade, a partir de determinadas normas sociais, crenças, tradições, convicções. Na interação com os outros, em um determinado contexto e situação social e cultural, são possíveis as trocas simbólicas e culturais. Os conteúdos simbólicos e as práticas culturais de contextos sociais específicos promovem, agenciam, permitem ou ponderam, dessa maneira, "determinadas emoções, ao mesmo tempo em que negam, restringem ou impõem interditos a outras, a partir das interações contínuas e constantes entre os sujeitos relacionais em trocas sociais determinadas" (KOURY, 2009, p. 9).

Por esse viés, a antropologia das emoções coloca em xeque as convicções modernas e ocidentais que consideram as emoções como universais. A compreensão das emoções na Antropologia parte do pressuposto de que as emoções são representações de uma dada sociedade, portanto, não são universais.

O pensamento da sociedade ocidental moderna é que as emoções são fenômenos comuns e naturais de todos os seres humanos, porque sentir emoções é possibilitado pelo equipamento biológico e psicológico inerente aos seres humanos. Nesse pensamento, as emoções trariam pouca ou nenhuma marca cultural e algumas pessoas seriam mais emotivas que outras, como mulheres, crianças e povos primitivos (REZENDE; COELHO, 2010). Para as autoras, as emoções estão situadas no corpo, mas não quer dizer que sejam naturais, porque o modo como entendemos e vivenciamos o corpo é sempre mediado pelas formas de pensar cultural e historicamente construídas.

As emoções, por estarem em um determinando contexto social, não são pensadas de forma isolada. Assim, há uma variedade cultural na forma de expressar as emoções. "As emoções tornam-se então parte de esquemas ou padrões de ação aprendidos em interação com o ambiental social e cultural, que são internalizados no início da infância e acionados de acordo com cada contexto" (REZENDE; COELHO, 2010, p. 30).

Portanto, as emoções, embora situadas no corpo, têm com este uma relação que é permeada sempre por significados culturalmente e historicamente construídos. A visão de que as emoções são fenômenos universalmente compartilhados, posto que fruto de uma unidade biológica e psicológica do ser humano, é problematizada pelas ciências sociais, que a toma como elemento da etnopsicologia ocidental moderna. (REZENDE E COELHO, 2010, p. 33).

São notáveis os avanços sobre a questão emocional em outras áreas do conhecimento, como apresentado anteriormente. As discussões sobre $o$ biológico e $o$ psicológico, além dos contextos sociais e culturais, têm ganhado destaque na temática. Bondi et al. (2007) acreditam que o termo "geografias emocionais" não deve ser entendido de forma estreita, uma vez que as emoções passam por e entre as 
fronteiras disciplinares, como já abordado anteriormente. Para os autores, é difícil imaginar qualquer área das Ciências Sociais ou Humanas que não possa ser enriquecida pela incorporação das emoções que estão tão intrinsecamente entrelaçadas com o tecido de nossas vidas. A geografia das emoções, nesse sentido, além de considerar os debates até então realizados, busca acrescentar outra proposta de análise sobre a questão: a dimensão espacial.

\section{Reflexões sobre a geografia das emoções}

Pesquisas recentes na Geografia vão apresentar a relação corpo e espaço a partir de uma outra perspectiva: a geografia das emoções. Tal proposta analisa a relação das pessoas e o espaço a partir das emoções, buscando compreender qual a dimensão emocional das representações espaciais, tendo, portanto, as pessoas como centralidade.

As relações entre os estados emocionais do ser e os espaços da vida cotidiana são apresentadas em diferentes perspectivas geográficas, no entanto, despertaram interesse em três principais perspectivas: humanista ${ }^{2}$, feminista ${ }^{3}$ e geografias não

\footnotetext{
2 "A crítica de que a Geografia humana privilegia a objetividade e a racionalidade às custas dos aspectos subjetivos da vida foi um brado de mobilização para a humanista há três décadas. Embora o termo 'emoção' possa não ter figurado de forma proeminente no trabalho dos geógrafos humanistas, o chamado para considerar as dimensões subjetivas da vida humana estimulou um corpo de pesquisa substancial que atendeu como as pessoas sentem e experienciam lugares e espaços (por exemplo, Buttimer; Seamon, 1980; Ley; Samuels, 1978; Rowles, 1978)". (Tradução livre; original em inglês: "The criticism that human geography privileges objectivity and rationality at the expense of subjective aspects of life was a rallying cry for humanistic geography some three decades ago. While the term 'emotion' may not have figured prominently in the work of humanistic geographers, the call to consider subjective dimensions of human life stimulated a substantial body of research that attended to how people feel and experience places and spaces").

3 "A indefinição da subjetividade humana também tem sido explorada substancialmente por geógrafos feministas em perspectivas que contribuíram para o surgimento de geografias emocionais, muitas vezes no contexto de estudos de corporeidade (LONGHURST, 2000, 2001), deficiência e doença crônica (DYCK, 1999; Moss, 1999) e problemas de saúde mental (PARR, 1999; DAVIDSON, 2003). Concentrando-se em experiências subjetivas problemáticas e muitas vezes 'deixadas de lado', essas pesquisas destacam como os limites corporais são produzidos, performados, desestabilizados e redesenhados em formas complexas e muitas vezes carregadas emocionalmente. Este corpo de trabalho aponta para conceitualizações da emoção como intrinsecamente fluidas, corporificadas e relacionais (ETTLINGER, 2004; BONDI et al., 2005)". (BONDI, 2005, p. 7). (Tradução livre; original em inglês: "The unboundedness of human subjectivity has also been explored substantively by feminist geographers in ways that have contributed to the emergence of emotional geographies, often in the context of studies of embodiment (LONGHURST, 2000, 2001), disability and chronic illness (DYCK, 1999; MOSS, 1999) and mental health problems (PARR, 1999; DAVIDSON, 2003). Focusing on troubled and often 'othered' subjective experiences, such research highlights how bodily boundaries are produced, performed, destabilised and redrawn in complex and often emotionally-charged ways. This body of work points towards conceptualisations of emotion as intrinsically fluid, embodied and relational").
} 
representacionais ${ }^{4}$, embora cada uma delas também tenha limites com relação ao debate (BONDI, 2005). Inclusive é a partir da crítica da geografia feminista e da geografia humanista, nos anos de 1970, sobre a pouca abordagem das emoções na Geografia e as tendências "desumanizadoras", que é apresentada a importância de um novo campo de estudos, com aportes na fenomenologia, no existencialismo e na geografia cultural, por exemplo.

Claramente as emoções importam, pois afetam a maneira como sentimos a substância dos nossos passado, presente e futuro, e têm o poder de transformar a forma de nossas vidas, expandindo ou contraindo nossos horizontes. Todavia, as experiências emocionais na geografia humana são tradicionalmente marginalizadas, a despeito de seu impacto em todos os aspectos de nossa vida social (WOOD; SMITH, 2004; BONDI et al., 2007).

Compreender a questão emocional na geografia é um desafio. Muitas vezes essa área de conhecimento nos apresenta um terreno emocionalmente estéril, um mundo desprovido de paixão, com espaços ordenados unicamente por princípios racionais e demarcados de acordo com lógicas políticas, econômicas ou técnicas, em que a negligência sobre o tema significa desconsiderar as relações com que as vidas são vividas e a sociedade é feita. Entretanto, em tempos e lugares particulares, há momentos em que as vidas são explicitamente vivenciadas pela dor, pelo luto, pela raiva, pelo amor e assim por diante, em que o poder das relações emocionais não pode ser ignorado. O mundo humano é construído e vivido através das emoções, e o silêncio sobre o tema tem se modificado com as recentes publicações, conferências e $\operatorname{cursos}^{5}$ dedicados à discussão e emerge como uma crítica aos que acreditam que as

\footnotetext{
4 "Comumente, a Geografia não representacional tem sido caracterizada por uma ponderação das formas de sentido-fazer que de alguma maneira poderiam afastar aquelas qualidades vagas de geografias rápidas e vivas que sempre excedem a representabilidade. Aqui reside o paradoxo da geografia não representacional: como nossos próprios textos podem sempre honrar o que está além do escopo do discurso? As geografias não representacionais do afeto não procuram resolver esse paradoxo, mas trabalhar com ele. Por exemplo, os contribuidores proclamam as qualidades performativas de suas próprias intervenções e recuam do avanço das afirmações interpretativas sobre as práticas com as quais se engajam (DEWSBURY, 2000, HARRISON, 2002, MCCORMACK, 2003)”. (BONDI, 2005, p. 9). (Tradução livre; no original em inglês: "More generally non-representational geography has been characterised by a wariness of forms of meaning-making that might somehow sequester those elusive qualities of quick and lively geographies that always exceed representability. Herein lies the paradox of non-representational geography: how can our own texts ever honour that which lies beyond the scope of discourse? Non-representational geographies of affect do not seek to resolve this paradox but to work with it. For example, contributors proclaim the performative qualities of their own interventions, and draw back from advancing interpretative claims about the practices with which they engage (DEWSBURY, 2000; HARRISON, 2002; MCCORMACK, 2003)".

${ }^{5}$ De acordo com Nogué (2015, p. 139), "Desde el año 2002 y cada dos años se celebra el Congreso Internacional e Interdisciplinar sobre geografías emocionales. Las sesiones del mencionado congreso tratan temas como los espacios afectivos y la globalización, el arraigo versus el desarraigo, las arquitecturas emocionales y los paisajes de la emoción, la semiótica y la poética del afecto, el espacio público y la emoción, y la política y la emoción, entre muchos otros". Além desse Congresso,
} 
emoções não são "materialmente" importantes (ANDERSON; SMITH, 2001; BONDI et al., 2007).

[...] Mas essa aparente ausência não é surpreendente, uma vez que as emoções nunca são simplesmente fenômenos superficiais, nunca são fáceis de definir ou demarcar, e não são facilmente observadas ou mapeadas, embora informem todos os aspectos de nossas vidas. Talvez seja melhor dizer que a geografia, como muitos de seus irmãos disciplinares, muitas vezes teve problemas para expressar sentimentos. As dificuldades em comunicar os elementos afetivos em jogo sob as topografias da vida cotidiana significaram que, em maior ou menor grau, a geografia tendeu a negar, evitar, suprimir ou minimizar seus emaranhados emocionais (BONDI et al., 2007, p. 1, tradução livre) ${ }^{6}$.

De acordo com Furlanetto (2014, p. 79), “A geografia emocional refere-se à experiência emocional e à leitura sensível dos lugares, às sensações e aos sentimentos que integram as paisagens", reforçando assim a importância do sentimento como característica essencial da existência humana no mundo ${ }^{7}$.

Pile (2010, p. 15) afirma que a geografia emocional:

comumente se preocupa com as emoções que as pessoas sentem umas pelas outras e, mais amplamente, por lugares, por paisagens, por objetos nas paisagens e em situações específicas. Em tais estudos, as pessoas expressam emoções sobre algo. Essas emoções são tomadas como pessoais, ainda que muitas vezes haja uma tentativa de encaixar essas emoções expressadas em um contexto mais amplo de emoções. Mesmo assim, uma compreensão deste contexto mais amplo é frequentemente construída fora das emoções expressadas pelas pessoas. Então, comumente, o espaço entre as pessoas é uma experiência direta e baseada na transmissão/recepção de sentimentos implícitos ou

recentemente foram publicadas importantes contribuições sobre o debate, destacando-se Davidson, J.; Bondi, L.; Smith, M. (Orgs.). Emotional Geographies (2007) e Emotion, Place and Culture (2009), bem como o periódico Emotion, Space and Society, em circulação desde 2008.

${ }^{6}$ Do original em inglês: "[...] But this apparent absence is hardly surprising since emotions are never simply surface phenomena, they are never easy to define or demarcate, and they not easily observed or mapped although they inform every aspect of our lives. Perhaps it would be better to say that geography, like many of its disciplinary siblings, has often had trouble expressing feelings. The difficulties in communicating the afftective elements at play beneath the topographies of everyday life have meant that, to a greater or lesser extent, geography has tended to deny, avoid, suppress or downplay its emotional entanglements (BONDI et al., 2007, p. 1)".

${ }^{7}$ Sobre isso, vale ressaltar que há relevantes contribuições teóricas que questionam a diferença entre emoções, sentimento e afeto. No entanto, nosso objetivo neste trabalho não é apresentar esse debate. Para isso, consultar, por exemplo, Pile (2010; 2011) e Damasio (2012). 
explícitos (seja de outras pessoas ou de objetos, como paisagens) [...] (tradução livre) ${ }^{8}$.

Bondi (2005) se propõe a pensar a emoção como um meio relacional, isto é, que medeia nossa relação com o espaço e no qual a pesquisa, pesquisadores e sujeitos de pesquisa estão necessariamente imersos. Nesse sentido, um verdadeira geografia das emoções busca compreender o envolvimento emocional com as pessoas e os lugares, em vez de seu distanciamento emocional (BONDI et al., 2007).

Andreotti (2013, p. 99) afirma que "a geografia emocional é uma geografia humanística inspirada, mais ou menos explicitamente, em diferentes doutrinas filosóficas, em especial a fenomenologia, o existencialismo, o espiritualismo e o pós-modernismo". A autora considera que essa perspectiva "favorece atenção às emoções, aos sentimentos e às sensações como fontes de conhecimentos e representações da superfície da Terra", sendo a discussão de desenvolvimento recente, com aportes na geografia da percepção e na geografia cultural.

A visão emocional acentua tonalidades, espaços e tempos. Investiga a escondida configuração de lugares e de paisagens, bem como experimenta a realidade valorizando a diversidade dos sentimentos e sentidos, modulados em relação a sua extraordinária polifonia. Compreende-se, assim, que estes animam a vida e dão formas e cores às emoções. Assume-se o real como um complexo perceptivo e fenomenológico. Não se consegue interpretá-lo, como muitas vezes tem sido feito, a partir de medidas matemáticas - volumes, parâmetros quocientes - que o empobrecem de significado. Neste sentido, não se sacrifica e/ou se reduz o real na racionalidade (ANDREOTTI, 2013, p. 99).

A proposta da geografia das emoções, portanto, busca interpretar o real para além das teorias matemáticas, comuns na ciência no geral e na geografia racionalista que, por sua vez, têm predominância de pressupostos positivistas, que consideram $o$ mundo como uma trama de relações causais, e cujo método é um empirismo indutivo, racionalista, decididamente antimetafísico. O interesse da geografia das emoções se dá pelo espaço vivido, que possui diferentes tonalidades e que não pode ser reduzido à racionalidade científica (ANDREOTTI, 2013).

\footnotetext{
${ }^{8}$ No original em inglês: "[...] commonly concerns itself with the emotions that people feel for one another and, more extensively, for places, for landscapes, for objects in landscapes and in specific situations. In such studies, people express emotions about something. These emotions are taken as personal, yet there is often an attempt to fit these expressed emotions into a wider context of emotions. Even so, an understanding of this wider context is frequently built up out of people's expressed emotions. Commonly, then, the space between people is one of direct experience, and based on the smooth transmission/ reception of tacit or explicit feelings (whether from other people or from objects such as landscapes) [...]".
} 
Na definição humanista, como mencionado, o objeto é o lugar e a paisagem, abertos às emoções e ao irracional, reconhecidos como predominantes nas relações que se entrelaçam. O objetivo já não é a explicação da realidade, mas sua compreensão baseada na potencialidade psicológica que tem. Renuncia-se ao raciocínio de forma lógica, ao argumentar de forma racional, para entender que significado tem o mundo na esfera existencial do homem e na escala de seus valores. (ANDREOTTI, 2013, p. 103).

Andreotti (2013) aponta as próprias transformações históricas como relevantes para a incorporação de novos temas na geografia, como a queda do muro de Berlim, a extinção da URSS, a virada dos anos de 1980 com relação aos sistemas de informação e a modernização sociocultural. Esses acontecimentos incorporam um "novo humanismo", com a ascensão de novas filosofias de vida e a consciência sobre os limites da atividade humana.

O problema das emoções atravessa toda a história do pensamento ocidental, desde a Antiguidade até hoje. A filosofia grega considera as emoções variações ou opiniões vazias da alma, o que não se altera até a idade moderna. Somente a partir deste período as emoções tornam-se um centro da experiência humana, em oposição à razão. Nós reconhecemos o sentimento como uma fonte ou princípio autônomo de afeições: uma categoria de análise. (ANDREOTTI, 2013, p. 101).

A psicologia, de acordo com Andreotti (2013), pode ser uma possibilidade de compreender as emoções, pois recupera na contemporaneidade a relação entre razão e emoção, trazendo à discussão a "inteligência emocional" e a "emoção racional". "As emoções são, portanto, aspectos fundamentais do ser", pois fazem parte da própria substância do homem, nos dizeres de Heidegger, isto é, estão na estrutura ontológica da existência.

A recente discussão da geografia emocional "toma a forma de uma geografia do espírito, dos sentimentos, mas também dos sentidos, dedicada às modalidades sensoriais que integram a nossa experiência no mundo" (ANDREOTTI, 2013, p. 101). Busca conectar-se aos lugares a partir de uma dimensão do invisível, sendo um projeto de psicogeografia, que alia a psique e a geografia.

A proposta dos geógrafos sobre a geografia das emoções é reconhecer as emoções como formas de saber, ser e fazer no sentido mais amplo, e usar isso para conduzir os conhecimentos geográficos além de suas formas habituais (ANDERSON; SMITH, 2001). Nesse viés, as pessoas tornam-se centrais na análise, e pensar o espaço geográfico vai além de sua dimensão material, concreta, palpável, 
mas também é possível incorporar as espacialidades e as relações topofílicas/topofóbicas com/nos lugares.

Para Bondi et al. (2007, p. 3), "uma geografia emocional, então, tenta compreender emoção - experiencial e conceitualmente - em termos de sua mediação e articulação socioespacial em vez de estados mentais completamente interiorizados"9 (tradução livre). A proposta do tema, portanto, não é trabalhar a questão emocional em si, mas sua relação com o corpo e os lugares, isto é, onde elas são sentidas e como e onde estão localizadas. Nossa interação emocional com os lugares e a vida, em essência, é emocional $e$ espacial. De maneira contínua, imbuímos os lugares de significados, que retornam a nós através das emoções que nos despertam (NOGUE, 2009).

Experimentamos emociones específicas en distintos contextos geográficos y vivimos emocionalmente los paisajes porque estos no son sólo materialidades tangibles, sino también construcciones sociales y culturales impregnadas de un denso contenido intangible. a menudo solamente accesible a través del universo de las emociones. (NOGUÉ, 2009, p. 22).

Na visão do autor, as topografias da vida cotidiana estão impregnadas de emoções e sentimentos, e nossas discussões geográficas não deixam de ser uma espécie de psicogeografias pessoais e sociais, em que é necessária a exploração das espacialidades da emoção, do sentimento e do afeto. Os lugares não são imóveis, pois viajam conosco através das emoções, que participam da nossa memória individual e coletiva. Assim, a geografia chegou até onde chegou graças a mais de meio século de consideração do elemento subjetivo na percepção e na vivência do espaço e, mais concretamente, da paisagem e do lugar, que seguem sendo os conceitos-chave nas geografias emocionais contemporâneas (vide os trabalhos de Eric Dardel, David Lowenthal, Edward Relph e outros, a partir dos anos de 1950).

[...] Unas [porciones da la superficie terrestre] son realmente minúsculas y aparentemente insignificantes por su tamaño y cotidianeidad: nuestra casa, una cafetería, una plaza, una esquina entre dos calles. Las esquinas de la ciudad, como otros tantos ínfimos rincones de la misma de aspecto anodino, pueden convertirse en lugares llenos de significado que encarnan la experiencia y las aspiraciones de la gente, evocan recuerdos y expresan pensamientos, ideas y emociones varias. El espacio

\footnotetext{
${ }^{9}$ No original em inglês: "An emotional geography, then, attempts to understand emotion - experientially and conceptually - in terms of its socio-spatial mediation and articulation rather than as entirely interiorised subjective mental states".
} 
geográfico, incluido el urbano, no es un espacio geométrico, topológico: es, sobre todo, un espacio existencial, conformado por lugares cuya materialidad tangible está teñida, bañada de elementos inmateriales e intangibles que convierten cada lugar en algo único e intransferible. Los lugares son los puntos que estructuran el espacio geográfico, que lo cohesionan, que le dan sentido. Los lugares no son simples localizaciones, fácilmente identificables en nuestros mapas a partir de un sistema de coordenadas que nos marca su latitud y su longitud. El lugar proporciona el medio principal a través del cual damos sentido al mundo y a través del cual actuamos en el mundo. Los seres humanos creamos lugares en el espacio, los vivimos y los imbuimos de significación. Nos arraigamos a ellos y nos sentimos parte de los mismos. Los lugares, a cualquier escala, son esenciales para nuestra estabilidad emocional porque actúan como un vínculo, como un punto de contacto e interacción entre los fenómenos globales y la experiencia individual. (NOGUÉ, 2015, p. 142-143).

Guinard e Tratnjek (2015) afirmam que, se as emoções são fatos sociais do passado e do presente, poderiam ser analisadas como fato espacial. Para as autoras, as emoções afetam não só o indivíduo, mas também a relação com os outros e com o espaço:

As emoções, na medida em que elas podem modificar a relação dos indivíduos e dos grandes grupos de indivíduos com o espaço, na medida em que elas podem ser traduzidas em seus corpos, suas representações e seus discursos, podem abrir pistas de estudos particularmente fecundas nos diferentes campos da geografia francesa contemporânea. (GUINARD; TRATNJEK, 2015, p. 2, tradução livre $)^{10}$.

As autoras defendem que, se as emoções podem ser coletivas, elas também são especializadas e materializadas, quer em lugares, quer em tempos e corpos.

As geografias das emoções parecem assim poder enriquecer nossa compreensão dos fenômenos espaciais, não somente porque elas dão atenção particular às experiências espaciais vividas pelo(s) sujeito(s), mas também porque se propõem a integrar uma dimensão sensível que frequentemente ainda faz falta às análises

\footnotetext{
${ }^{10}$ No original em francês: "Les émotions, en tant qu'elles peuvent modifier le rapport des individus et des groupes d'individus à l'espace, en tant qu'elles peuvent avoir des traductions dans leurs corps, leurs représentations et leurs discours, peuvent ouvrir des pistes d'études particulièrement fécondes dans les différents champs de la géographie française contemporaine.
} 
geográficas, e isso principalmente por razões metodológicas. (Olmedo, 2011, s/p apud GUINARD; TRATNJEK, 2015, p. 3, tradução livre) ${ }^{11}$.

As questões emocionais, por vezes, são interpretadas como algo relacionado à esfera privada, isto é, como se estivessem apenas no interior do indivíduo, expressadas em espaços privados. Mas é notável que em todas as nossas relações sociais evocamos nossas emoções (ANDERSON; SMITH, 2001). Os autores afirmam que nossas emoções são evocadas em determinados momentos e lugares, nos quais muitas vivências do nosso cotidiano são explicadas a partir de dor, raiva, amor, exaltação, e não podem ser ignoradas. A tentativa da geografia das emoções em trabalhar com esses espaços explicitamente emocionais contrasta com os modelos convencionais de pesquisa social, que por vezes priorizam os comportamentos políticos, a racionalidade econômica, as relações de classe, cujo conteúdo emocional é minimizado.

Para Pile (2010) há várias formas de intervenção e observação para compreender esses sentimentos. Preocupada com a proximidade e a intimidade, a geografia afetiva e emocional procura uma perspectiva metodológica, uma etnografia, variando entre observação e participação. É importante não converter as questões emocionais em mera conceitualização, deixando de lado a questão real. Assim, as narrativas são fundamentais, onde o corpo torna-se peça-chave.

Sobre isso, a contribuição da geografia das emoções também ocorre do ponto de vista metodológico, visto que o envolvimento do pesquisador é diferente, não somente com um olhar objetivo sobre a questão, mas aberto à ampla gama de emoções que a pesquisa envolve a partir da relação que tece com os sujeitos dessas pesquisas (conversas, interações). Essa perspectiva insiste na importância de "dar voz" aos indivíduos marginalizados, daí o uso frequente de citações textuais de transcrições de entrevistas em profundidade (BONDI, 2005).

Consequentemente, as questões de como representar a emoção exigem que aqueles envolvidos na construção de geografias emocionais considerem a questão emocional também através da escrita e da leitura de seus textos, bem como em suas áreas de estudo, já que, em maior ou menor grau, a escrita acadêmica articula as preocupações e paixões de seus autores, mas os gêneros acadêmicos tradicionais procuram excluir sua expressão explícita. Uma gama de recursos teóricos está disponível para apoiar tal pensamento, como a influência da fenomenologia, em que

\footnotetext{
${ }^{11}$ No original em francês: "Les géographies des émotions semblent donc pouvoir enrichir notre compréhension des phénomènes spatiaux, non seulement parce qu'elles portent une attention particulière aux expériences spatiales vécues par le(s) sujet(s), mais aussi parce qu'elles se proposent d'intégrer une dimension sensible qui fait encore souvent défaut aux analyses géographiques, et ce principalement pour des raisons méthodologiques".
} 
cada vez mais os acadêmicos têm procurado experimentar estilos emocionalmente mais expressivos (BONDI et al., 2007).

Sobre esse aspecto, Guinard e Tratnjek (2016) apontam também as emoções como uma manifestação da subjetividade do pesquisador, sendo um convite para entender sua própria relação com o espaço, para melhor perceber sua prática e seu lugar no mundo, além de entender sua própria relação com os outros e como desenvolve suas relações intersubjetivas.

Apreender nossas emoções, não como um meio, mas como uma expressão do que nos conecta com o mundo e com os outros, permitiria assim melhor dar conta da forma como produzimos nosso espaço, como fazemos geografia. [...] A questão das emoções do pesquisador é interessante e particularmente estimulante, na medida em que pode ser uma indicação de uma certa evolução da disciplina nesse tema, mas também de uma evolução na forma como os geógrafos se posicionam frente à disciplina e para além dela. $O$ fato de evocar as emoções já não é na verdade uma forma de engajamento do investigador na disciplina e no mundo? (GUINARD; TRATNJEK, 2016, p. 1112 , tradução livre $)^{12}$.

Em suma, Bondi (2005) afirma que as emoções fazem parte da vida humana e que os geógrafos não podem ignorar essa questão. No entanto, corre-se o risco de que as abordagens geográficas sobre o tema sigam o caminho de tendências culturais que tratam as emoções como atributos individualizados disponíveis para exploração política e comercial. O autor afirma que uma maneira de a Geografia não “cair" nesse problema é explorar as emoções a partir de uma visão holística sobre a subjetividade, proposta pela geografia humanista, que proporcionou um impulso importante no sentido de se envolver com dimensões emocionais de experiências de lugar e espaço das pessoas.

Consideramos que as discussões sobre a questão emocional estão muito relacionadas ao ser humano, ao corpo, às relações interpessoais, às questões biológicas, psicológicas, isto é, o indivíduo em si e a partir de suas relações sociais. A geografia das emoções busca articular essas pesquisas clássicas, colocando seu ponto de vista, analisando as emoções a partir das relações sociais e das práticas espaciais.

\footnotetext{
${ }^{12}$ No original em francês: "Appréhender nos émotions, non comme un biais mais comme une expression de ce qui nous relie au monde et aux autres, permettrait alors de mieux rendre compte de la manière dont nous produisons notre terrain, dont nous faisons de la géographie. [...] a question des émotions du chercheur est intéressante et particulièrement stimulante, en ce que cela peut être l'indice d'une certaine évolution de la discipline à ce sujet mais aussi d'une évolution de la façon dont les géographes se positionnent vis-à-vis de la discipline et au-delà de celle-ci. Le fait d'évoquer ses émotions, n'est-ce pas en effet déjà une forme d'engagement du chercheur dans la discipline et dans le monde? ".
} 


\section{Introdução do sensível para pensar a cidade}

Recentemente, houve um maior interesse da geografia em explorar temas relacionados às questões emocionais, o que caracterizou a geografia social e cultural da última década. As emoções têm capacidade de circular por toda a geografia, como, por exemplo, na geografia social, na geografia cultural, na geografia política, na geografia urbana, na geografia do turismo e do patrimônio e nos estudos ambientais, constituindo-se como um objeto transversal da ciência geográfica (GUINARD; TRATNJEK, 2016).

Dentre os temas presentes na discussão da geografia das emoções podemos citar experiências emocionais relacionadas com problemas psicológicos; lugares e emoções relacionados ao luto; o turismo e a relação emocional com os lugares; experiências emocionais relacionadas à velhice, os idosos e seus lugares de memória; cartografias emocionais; alteridade; intimidade; estudos relacionados à paisagem e às questões sensoriais; paisagens urbanas; espaços públicos e espaços privados; estudos do corpo, questões estéticas, práticas terapêuticas; o medo relacionado à violência em espaços urbanos e às questões de gênero ${ }^{13}$.

Guinard e Tratnjek (2016) afirmam que, apesar das diferenças relacionadas com o tema, um número de pontos em comum pode ser encontrado nas pesquisas que discutem as emoções: 1) o fato de que elas são um tipo de estado afetivo; 2) a sua capacidade para exteriorizar; 3) a sua relativa curta temporalidade, 4) a sua capacidade para criar uma ação; 5) o caráter contextual. Essas convergências enriquecem as definições e nos permitem confirmar e fortalecer a dimensão espacial das emoções, em que se justifica uma abordagem emocional como fenômenos afetivos que ocorrem no espaço, os quais induzem uma configuração de movimento no espaço e que são específicos para o tempo e os espaços individuais.

Muitas das produções se beneficiaram de trabalhos anteriores, que tinham a discussão do corpo como centro, já que é o local de expressão e experiência emocional por excelência. Conforme Davidson e Milligan (2004), as emoções definitivamente ocorrem dentro e ao redor desta escala espacial mais próxima (o corpo).

Para a geografia emocional, o corpo é o lugar dos sentimentos e da experiência, que são socialmente integrados, mas é no corpo que eles estão localizados. Embora embutida nas relações sociais, é em última análise pessoal: é a localização do sujeito psicológico. Na geografia afetiva, o corpo não pode ser visto como pessoal, mas

\footnotetext{
${ }^{13}$ Alguns desses temas podem ser encontrados nas produções Emotional Geographies (2007), Teoría y paisaje II: paisaje y emoción. El resurgir de las geografias emocionales (2015), Carnets de Géographes: dernier numéro en ligne 'Géographies des émotions' (2016), além das contribuições da revista Emotion, Space and Society.
} 
como transpessoal. O corpo tem o desafio de expressar as emoções, sendo a localização do não psicológico. Seja qual for o contexto histórico e cultural particular, a base de sua experiência geográfica é o extrato corporal pré-reflexivo de sua vida - seu espaço corporalmente vivido (PILE, 2010).

Nossas experiências emocionais no espaço são mediadas através do corpo. É a partir do corpo que nos comunicamos com o espaço, construímos nosso mundo vivido, em que as emoções sempre estão presentes. A partir do nosso corpo, agimos no espaço e criamos distintas espacialidades. Assim, corpo, ação, emoção e espaço estão intrinsicamente relacionados.

Algumas análises relevantes fazem a conexão corpo e espaço. Exemplo disso é tradição filosófica que nasce da perspectiva fenomenológica de Merleau-Ponty, que aponta a inseparabilidade do eu e do mundo, oferecendo uma análise da percepção como o cimento da experiência humana. O filósofo expressa a relação íntima do corpo e do mundo, onde o espaço revela-se a si mesmo através dos gestos corporais, criticando ainda a ciência tradicional, que não se interessou em discutir a interação entre corpo e espaço, visão e movimento, buscando assim uma compreensão holística do mundo.

Para Merleau-Ponty (1999, p. 328), “o espaço não é o ambiente (real ou lógico) em que as coisas se dispõem, mas o meio pelo qual a posição das coisas se torna possível". Nesse sentido, o espaço é como a superfície da existência, apreendido por meio da experiência perceptível (corpo), isto é, a experiência espacial é corporal e vice-versa. Assim, o corpo, sendo nosso meio de comunicação, revela-nos ao mundo.

Lindón (2009) aponta que em seus estudos não é abordado o corpo ou as emoções em si mesmos, mas em relação com outras dimensões. Estuda o corpo e as emoções como uma janela para compreender a construção social da cidade, do urbano e dos lugares, através dos sujeitos que habitam esses lugares.

Desde este campo del saber, aun en proceso de hacerse, se observa una asignatura más o menos pendiente: el reconocimiento de que el sujeto, con su corporeidad y emociones, también habita lugares que se hacen parte de lo social, del cuerpo que allí está y de las emociones experimentadas por dichos cuerpos. En otras palabras, los estudios más consolidados sobre el cuerpo, la corporalidad y las emociones suelen olvidar la espacialidad, aunque paradójicamente la relación entre el cuerpo y el espacio es inevitable para la condición humana. De igual forma, la relación entre el espacio y las emociones constituye otro aspecto ineludible de la vida misma. (LINDÓN, 2012, p. 701).

A autora explora uma série de transversalidades e intersecções analíticas entre o corpo, as emoções, a cidade e a espacialidade. Uma dessas transversalidades é colocar a centralidade do sujeito como construtor do social, pensando não só a 
materialidade, mas também a imaterialidade da vida urbana. Para tanto, Lindón (2009) aponta alguns termos que justificam este viés de análise: o sujeito-habitante (construtor do social e do urbano, em particular), o sujeito-corpo (sujeito-habitante em sua corporeidade) e o sujeito-sentimento (envolvido pelas emoções). A autora sugere compreender tais relações a partir da análise de "microssituaciones" que, embora possam expressar o específico, também expressam singularidades, sendo que "por medio del microanálisis, dan cuenta de distintos tipos de procesos de producción/reproducción socio-espacial que se desarrollan en la ciudad, y que la configuran y reconfiguran de manera constante" (LINDON, 2009, p. 6).

Essas microssituações são expressas a partir de alguns tipos de sujeito-corpo e sujeito-sentimento que são parte do cenário urbano e da construção socioespacial da cidade. Lindón (2009) os categoriza como:

- sujeito-corpo como objeto de deslocamento (a lógica espacial é a de "passar"; trajeto espacial e transcurso temporal);

- sujeito-corpo como meio de uma certa prática (utilitário; ex.: vendedor ambulante);

- sujeito-corpo como elemento estético do lugar (corpo e visibilidade espacial; ex.: observador);

- sujeito-corpo como expressão de desencaixe (o sujeito-corpo expressa a transgressão dos códigos sociais que estão ancorados no lugar e nas pessoas; ex.: estudos de geografia de gênero abarcam essa questão);

- sujeito-corpo como expressão espacial da exclusão: sujeito-corpo como expressão do lugar reivindicado (lógica corporal é do tipo territorial);

- sujeito-corpo alcança uma identificação/identidade a partir de uma prática de estar no lugar, de pertencer a ele (o sujeito-sentimento se impõe sobre o sujeito-corpo; a lógica espacial é de pertencer ao lugar, e a temporalidade geralmente é prolongada);

- sujeito-corpo como construtor de distâncias espaciais com os outros e de afastamento do lugar (a lógica corporal é do tipo topofóbica).

Além desta discussão, Lindón (2009) levanta a questão das subjetividades espaciais, expressas pela narrativização e pelos imaginários urbanos. De acordo com a autora:

En virtud de esa narrativización, la vida urbana, con su constante fluir, circula ideas, imágenes, códigos. Pero, todo esto ocurre de una manera particular: se omite verbalizar quién ha planteado esa idea, o el código de comportamiento, o algún sentido atribuido a un lugar, y así se constituye implícitamente un mecanismo que le otorga fuerza a la idea misma. A veces esas ideas y códigos adquieren el carácter de "verdad", de plausibilidad, por haberse independizado de quién la expresó. Esas ideas independizadas de 
su autor emergen en las microsituaciones del sujeto cuerpo y sentimiento. De modo tal que las microsituaciones no deberían verse como instancias en donde los fragmentos de ciudad se hacen y rehacen de manera enteramente libre por parte de los actores territorizados, sino más bien en tensión permanente entre esas verdades asumidas y otras formas de hacerlas que van surgiendo y negociándose en cada microsituación. (LINDÓN, 2009, p. 10).

Nesse sentido, propomos pensar uma geografia das emoções nos lugares, especialmente no espaço urbano, no intuito de possibilitar aos geógrafos e planejadores a reflexão crítica sobre a questão urbana, indo além das concepções clássicas que dizem respeito somente aos propósitos materiais e funcionais da cidade, desconsiderando por vezes questões mais subjetivas do habitar, do cotidiano e do espaço vivido das pessoas.

Um exemplo pertinente sobre isso são as inúmeras expulsões de moradores de determinados espaços na cidade, para dar lugar a uma avenida (e propiciar a melhor circulação de carros) ou a um shopping center (estimulando o consumo e segregando as pessoas), onde são obrigados a ir para as periferias urbanas, que geralmente não possuem o básico do direito à cidade. Pior do que isso são as memórias, lembranças, histórias, permeadas pelas emoções, que são desconsideradas quando há esse tipo de ação na cidade.

Outro exemplo são as modificações dos bairros, ruas ou de outros lugares importantes para as pessoas sem que haja um mínimo de participação delas nas decisões, desconsiderando novamente a relação dessas pessoas com esses lugares. A (re)produção do espaço urbano, na lógica de acumulação do capital, é produto social, comumente influenciada por estratégias de determinados atores sociais. A lógica busca os melhores lugares, mais rentáveis, numa dinâmica de relações de produção e estrutura de poder. Nesse contexto, embora o olhar sobre o local tenha sido ampliado, as vivências, experiências e questões mais subjetivas relacionadas aos indivíduos e ao coletivo são claramente desconsideradas.

Nesse sentido, numa abordagem mais existencialista, Sartre afirma que:

Já podemos, agora, conceber o que é uma emoção. É uma transformação do mundo. Quando os caminhos traçados se tornam demasiado difíceis ou quando não vemos caminho algum, verificamos que não podemos continuar num mundo tão urgente $\mathrm{e}$ tão difícil. Todas as vias são barradas, e, apesar disso, é preciso agir. Tentamos, então, mudar o mundo, isto é, tentamos viver como se as relações entre as coisas e as suas potencialidades não fossem governadas por processos deterministas, mas pela magia. (SARTRE, 2006, p. 10). 
Assim, a geografia das emoções pode despertar a importância da dimensão sensível existente em nossas práticas, experiências e vivências espaciais, percebendo os lugares não só como pano de fundo das relações sociais, mais fundamentais para compreender os sujeitos, possibilitando uma compreensão "mágica" do nosso serno-mundo.

\section{Considerações finais}

Compreender as questões mais subjetivas na geografia não é proposta relativamente recente. Desde a década de 1970, como uma crítica à geografia positivista, as questões mais "humanas" têm sido colocadas como centrais em determinadas discussões, como a geografia humanista, a cultural e a feminista. A geografia das emoções, no entanto, é uma proposta mais atual e tem ganhado destaque na Europa e na América do Norte. No Brasil, há poucas abordagens específicas sobre o tema, o que possibilita discutir e avançar na sua compreensão.

Mostra-se ainda pertinente o diálogo com outras áreas do conhecimento, em que o estudo sobre as emoções já está avançado. A partir das leituras realizadas, foi possível perceber que a geografia das emoções se apropria de muitos desses discursos, mas coloca a questão espacial como essencial para compreender as emoções sob outro viés.

É notável que há muito o que se discutir sobre o assunto, e a agenda da geografia das emoções é ampla. Dentre os assuntos pertinentes a serem tratados, a partir da perspectiva da geografia das emoções, podemos citar: a dimensão emocional das representações espaciais; a relação emoção, espaço e fobias; as experiências emocionais vividas por grupos marginalizados no espaço urbano (comunidade LGBT no geral, travestis, negros, pessoas em situação de rua); debates interseccionais; diferentes emoções em crianças, jovens e idosos; experiência emocional e espacial em pessoas com deficiências ou determinadas doenças; mapeamento das emoções (cartografias afetivas e emocionais); emoções a partir de narrativas; a relação entre mobilidade (forçadas, intencionais; imigrantes, campocidade) e as emoções; relação das emoções com espaços e lugares de memória.

Assim, este trabalho mostra-se como uma introdução à discussão, pois, dada a complexidade do tema, ainda há muito o que desbravar a partir da perspectiva da geografia das emoções. De maneira objetiva e concisa, buscamos apresentar a discussão e instigar outros geógrafos a pensarem uma outra geografia, a partir de um olhar sensível e, de certa forma, como afirmou Sartre, mágico. 


\section{Referências}

ANDREOTTI, Giuliana. (2013) Geografia emocional e cultural em comparação com a racionalista. In: HEIDRICH, Álvaro Luiz; COSTA, Benhur Pinós da; PIRES, Cláudia Luisa Zeferino (Orgs.). Maneiras de ler geografia e cultura. Porto Alegre: Imprensa Livre: Compasso Lugar Cultura, p. 98-105.

ANDERSON, Kay; SMITH, Susan. (2001) Editorial: Emotional Geographies. Transactions of the Institute of British Geographers, Reino Unido, vol. 26, n. 1, p. 7-10.

BONDI, Liz; DAVIDSON, Joyce; SMITH, Mick. (2007) Introduction: Geography's Emotional Turn. In: DAVIDSON, J.; BONDI, L.; SMITH, S. (Orgs.). Emotional Geographies. Farnham: Ashgate, p. 1-16.

BONDI, Liz. (2005) Making connections and thinking through emotions: between geography and psychotherapy. Transactions of the Institute of British Geographers, Reino Unido, vol. 30, n. 4, p. 433-448.

DAMASIO, António. (2012) O erro de Descartes. Emoção, razão e cérebro humano. São Paulo: Companhia das Letras. 264 p.

DAVIDSON, Joyce; MILligAN, Christine. (2004) Embodying Emotion Sensing Space: Introducing emotional geographies. Social \& Cultural Geography, vol. 5, n. 4, p. 523-532.

FRANCISCO, Paulo Roberto. (1998) Emoções e personalidade. In: BERTOLINO, Pedro et al. As emoções. Florianópolis: NUCA Edições Independentes, p. 145-159.

FURLANETTO, Beatriz Helena (2014) Paisagem sonora do boi-de-mamão no litoral paranaense: a face oculta do riso. Tese de Doutorado em Geografia. UFPR, Curitiba, $212 \mathrm{p}$.

GUINARD, Pauline; TRATNJEK, Benedicte. (2015) Géographies, géographes et émotions. Appel à contributions pour le neuvième numéro des Carnets de Géographe. Paris, p. 1-8.

- (2016) Géographies, géographes et émotions. Carnets de Géographes: Géographies des emotions. Paris, n. 9, 2016, p. 1-16.

KOURY, Mauro Guilherme Pinheiro (2009). Emoções, sociedade e cultura: a categoria de análise de emoções como objeto de investigação na Sociologia. Curitiba: CRV. 104 p.

LINDÓN, Alicia. (2009) La construcción socio-espacial de la ciudad. Desde la perspectiva del sujeto-cuerpo y el sujeto sentimento. Anais XXVII Congreso de la Asociación Latinoamericana de Sociología. Asociación Latinoamericana de Sociología, Buenos Aires, p. 1-11.

- (2012) Corporalidades, emociones y espacialidades. Hacia un renovado betweenness. Revista Brasileira de Sociologia da Emoção, João Pessoa, v. 11, n. 33, p. 698-723.

MERLEAU-PONTY, Maurice (1999). A fenomenologia da percepção. $2^{\mathrm{a}}$ ed. São Paulo: Martins Fontes. 
NOGUÉ, Joan. (2009) Geografías emocionales. Culturais. La Vanguardia. Maio, p. 22.

. (2015) Emoción, lugar y paisaje. In: LUNA, Toni; VALVERDE, Isabel. Teoría y paisaje II: paisaje y emoción. El resurgir de las geografias emocionales. Observatorio del Paisaje de Cataluña. Barcelona: Universidad Pompeu Fabra, p. 137-148.

OATLEY, Keith; JENKINS, Jenniffer. (2002). Compreender as emoções. Lisboa: Instituto Piaget, 2002. $516 \mathrm{p}$.

PILE, Steve. (2010) Emotions and affect in recent human geography. Transactions of the British Geographers. Reino Unido, NS 35, p. 5-20.

. (2011) For a geographical understanding of affect and emotions. Transactions of the Institute of British Geographers. Reino Unido, NS 36, p. 603-606.

RAGASSI, Doroti M. M. (1998) O estudo fenomenológico da emoção. In: BERTOLINO, Pedro et al. As emoções. Florianópolis: NUCA Edições Independentes, p. 99-130.

REZENDE, Claudia Barcellos; COELHO, Maria Claudia. (2010). Antropologia das emoções. Rio de Janeiro: FGV. 136 p.

SARTRE, Jean-Paul (2006) Esboço para uma teoria das emoções. Porto Alegre: L\&PM. 96 p.

SMITH, M.; DAVIDSON, J.; CAMERON, L.; BONDI, L. (2009) Geography and emotion - emerging constellations. In: SMITH, M. et al. (Eds.). Emotion, Place and Culture. Farnham: Ashgate, p. 1-17.

TEIXEIRA, Cláudia Félix. (1998) A emoção como fenômeno singular/universal. In: BERTOLINO, Pedro et al. As emoções. Florianópolis: NUCA Edições Independentes, p. 131-143.

WOOD, N.; SMITH, S. (2004) Instrumental routes to emotional geographies. Social and Cultural Geography, Reino Unido, n. 5, p. 533-548.

Data de submissão: 04/02/2016.

Data de aceite: 12/12/2016. 